DOI: 10.31695/IJASRE.2022.8.2.13

\title{
Website Development: The Case of Agricultural Extension Providers in Tanzania
}

\author{
Victor Ngessa ${ }^{1}$, Kisangiri F. Michael ${ }^{2}$, Kelvin Mark Mtei ${ }^{3}$, and Mawazo Mwita Magesa ${ }^{4}$ \\ Research Scholar ${ }^{1}$, Senior Lecturer ${ }^{2}$, Professor $^{3}$, Senior Lecturer ${ }^{4}$ \\ ${ }^{1,2}$ School of Computational and Communication Science and Engineering, \\ ${ }^{3}$ School of Materials, Energy, Water and Environmental Sciences, \\ Nelson Mandela African Institution of Science and Technology, Arusha, Tanzania \\ ${ }^{4}$ Department of Informatics and Information Technology, \\ College of Natural and Applied Sciences, \\ Sokoine University of Agriculture, Morogoro, Tanzania
}

\begin{abstract}
This study examined current practice in websites development among organizations in Tanzania that provide agricultural extension services to smallholder farmers. Google search was used to get a list of respondent organizations. A questionnaire, interviews, and a review of the websites owned by organizations under study were used to collect data. Other than websites, it was found that organizations use manual documents, physical visits, radios, SMSs, TVs, and social networks to disseminate information to smallholder farmers. Websites development was either done in-house or outsourced and the focus was to have websites that cater to the information needs of different stakeholders including smallholder farmers. Information on websites included contacts, announcements, specific information for farmers, with some of the information not directly relating to smallholder farmers. This led websites to contain lots of information which might affect the usability of those websites by smallholder farmers hence not benefiting from the information contained. This was the case for all websites. Also, the involvement of smallholder farmers during website development was low. Websites for agricultural extension providers were developed either in-house or outsourced. The government-owned agency (e-GA), commercial companies, and staff were among developers for the websites. Communication between stakeholders during the development process was easier for in-house development as compared to when websites were developed outside. Websites developed were either internally maintained or maintained outside organizations, with internal maintenance being cheaper compared to when maintenances were done outside organizations. To develop quality websites from smallholder farmers' point of view their involvement should be high and the websites and the contained information should be easier to access with minimal information. Also, websites should be professionally designed and developed to focus more on the provision of agricultural extension services.
\end{abstract}

Key Words: Website development, Smallholder farmers, ICT in agricultural extension, Agriculture in Tanzania.

\section{INTRODUCTION}

According to the Food and Agriculture Organization of the United Nations [1] about 90\% of the World's 570 million farms are small, operated by smallholder farmers and are found in rural areas of developing economies. Studies have shown that smallholder farmers in developing economies face a number of challenges and are in need to improve farm productivity, get more profit and improve their quality of life [2-4]. Agricultural extension is vital in ensuring that smallholder farmers get knowledge and skills necessary in improving farming practices [5].

But studies have shown that traditional extension services face challenges and have not been able to meet agriculture information needs of smallholder farmers in developing economies [6-8]. For example [6] study points that governments extension services agencies are most of the time bureaucratic and normally their services cannot reach all smallholder farmers, are not up to date and not tailored for the needs of the smallholder farmers. To overcome challenges associated with current agricultural extension 
services, stakeholders in the agriculture industry have been developing websites and other information systems to provide extension services needed by smallholder farmers.

According to [9] and [10] Information and communication technologies (ICTs) trends in usage of smartphones and network connectivity in both urban and rural areas of developing economies has been promising. These two together with capability in using smartphones are necessary to ensure access of information contained in websites.

Websites can be used to replace manual documents prepared by agricultural extension personnel like fliers, leaflets, books, and brochures for the aim of imparting knowledge and skills to smallholder farmers. Advantages of websites include speed, convenience, increase in profit and capability to provide information in varied format and easy to update [11]. Also websites provide exceptional opportunities for information sharing and linking with other stakeholders and e-learning is specifically interesting for educational purposes [6]. However, a systematic literature review by [12] shows that except for two agricultural projects - Community Knowledge Workers (CKW) for Rural Advisory Services in Uganda and Sauti ya Wakulima in Tanzania other projects do not use smartphones and hence farmers cannot get advantages websites offer. Even if all projects had used websites as one of their mechanisms to disseminate information, but website design and usage is a challenge. It is pointed out in a study [13] that many years of working in the area of website design and development has not helped in achieving desired quality of websites developed as the literature shows that they still fail to deliver desired goals.

According to the Global Forum for Rural and Agricultural Services [14] major institutions providing agricultural extension services in Tanzania include: public sector (like the Ministry of Agriculture and public research institutions), private sector firms, Non-governmental Organizations (NGOs) and other donors, and farmer-based (community-based) organizations and cooperatives. These institutions have websites used among others to disseminate information to smallholder farmers. This study examined the existing practice in website development among these providers of agricultural extension services to smallholder farmers who own websites in Tanzania. Specifically, the study determined; agricultural information dissemination methods used, how activities are conducted before and during website development and how website maintenance is done.

\section{LITERATURE REVIEW}

\subsection{Agricultural Extension}

IGI-GLOBAL dictionary [15] defines Agricultural extension as "the rendering of assistance for application of scientific research at farm level to boost agricultural productivity and agriculture livelihood security." The Food and Agriculture Organization of the United Nations [16] notes that agricultural extensions are associated with informal educational processes directed toward the rural inhabitants, change farmers' outlook toward their difficulties and work with rural population in order to improve their standards of living. Generally, agricultural extension is responsible in boosting agricultural productivity, increasing food security, and improving rural livelihoods.

\subsection{Website}

According to MERRIAM-WEBSTER dictionary [17] a website is a group of World Wide Web pages mostly with links to connect to each other and made available online for its access. Individuals, institutions, governments and other organizations have websites and make them available online for its information to be accessed over the internet. According to Collins English dictionary [18] a website contains a set of data or information (content) about a particular subject and is available over the internet. Contents on the website are held in the webserver which is a software and its underlying hardware responsible for storing the content, processing requests for access of the contents and delivering or denying access to the contents [19].

\subsection{Overview of ICT usage in Agricultural Information Dissemination}

China's agriculture sector has been transformed from the traditional to modern practice through the effective deployment of Information and communication technologies (ICTs) [20]. The study further reveal that ICT Agricultural information dissemination models used in China include: Web Portals - collections of relevant websites, Voice-Based Service - information dissemination through telephone, Text - Short Message Service (SMS) - Based Service - information dissemination through text message of mobile phones, Self-Support Online Community - information services provided by a community to its members, Interactive Video Conferencing Service - using online multimedia technology to facilitate information service, and Mobile Internet Based Service - information dissemination through smart phone service. Use of ICT based information dissemination to provide easy access to information, knowledge and expert support have enabled farmers to improve their income and economic situation through better practice, for example in dealing with natural disasters, pests, trading, marketing, and with raising awareness of government support and favorable policies [20]. The study is supported by other studies like that of [21] which point that farmers in the Upper West Region of Ghana generally rate weather and market information disseminated through mobile phones as very useful. The study recommends ICT information to be constantly updated to reflect current conditions and also to 
be more targeted. However, [22] study found that rural farmers have limited access to agriculture information disseminated through ICTs.

\subsection{Framework for Website Design and Development}

This study adopted a [13] website design and development framework. This framework constitutes phases that act as guidance on website design and development process. The phases are: identifying objectives, design, development, and implementation. In the initial phase of identifying objectives, objectives or requirements for developing the website are determined and evaluated for their worthiness. The second phase involves designing the website where simplicity and ease of use are important issues to be considered. The design, among others, involves creating blueprints for the interface and establishing links between individual pages of the website. In the development phase actual creation of databases (if the website will be database driven) and coding take place. This is the construction of the system that users will be interacting with. According to [13] framework the last phase is implementation where the website will be launched to the World Wide Web for users' access using their devices. This phase also entails maintenance issues carried to ensure the website operates as expected.

This framework is based on traditional information systems development models like Waterfall, V-process, Rapid action development (RAD), and Spiral models. The models outline information systems development processes from planning and identifying requirements up to development and later maintenance [13][23-25]. Each of the information systems development models has its own strengths and weaknesses with some models better fitting particular projects than others [24-25]. The [13] framework was used to frame this study by identifying phases for website design and development and map them to guide preparation for data collection tools for this study.

\section{RESEARCH METHODOLOGY}

Respondents were from nine regions of Tanzania, which is a country found in East Africa between the latitudes of $1^{\circ}$ and $12^{\circ} \mathrm{S}$ and longitudes $30^{\circ}$ and $40^{\circ} \mathrm{E}$ [26]. The regions are: Arusha, Dar es Salaam, Dodoma, Iringa, Kilimanjaro, Lindi, Morogoro, Tabora, and Tanga. A total of 21 organizations from these regions were consulted. These are public and private organizations that deal with provision of extension services to smallholder farmers and have websites.

A questionnaire with closed and open ended questions was developed and sent physically, and in few cases emailed after phone contacts for introduction. Online Google form was prepared for those who could fill it. Selected website owners were interviewed for detailed information and websites were analysed to check for quality and information contained.

Google search engine was used to get a list of respondent organizations. These were organizations located in Tanzania, that were in the agriculture industry, public or private and providing extension services to farmers. The following Keywords were used to find respondent organizations: "mafunzo kwa wakulima", "agricultural extension in Tanzania", "Kilimo Tanzania", and "farmers training in Tanzania". The displayed search results were each opened to check suitability for the study.

Websites of organizations outside Tanzania and those whose focus were not on provision of any kind of agricultural extension services to smallholder farmers were not included for the study. Examples of websites not included for study were those dealing with sales and marketing of crops only. The following information: organization name, website uniform resource locator (URL) address, phone number(s), email addresses and physical addresses were obtained.

Of the 21 organizations involved in the study, $14 \%$ had fewer than 10 employees, $43 \%$ had between 10 and 49 employees, $33 \%$ had between 50 and 249 employees and 10\% had above 250 employees (approximately). This categorization of organizations is based on the European Commission [27] which classifies organizations based on the number of employees. Table 1 shows another categorization of organizations.

Table 1: Organizations involved in the study

\begin{tabular}{ll}
\hline Category & Percentage (Sample size = 21) \\
\hline Under Ministry of Agriculture (MoA) & 47.6 \\
Under other Ministry other than Ministry of Agriculture & 4.8 \\
Non-government Organization (NGO) & 38.1 \\
Public Private Partnership (PPP) & 4.8 \\
Private Agribusiness & 4.8 \\
\hline
\end{tabular}


Public institutions include the Ministry of Agriculture, agriculture research institutions, boards and other institutions under the Ministry of Agriculture. Quantitative as well as qualitative data analysis methods were adopted.

\section{RESULTS AND DISCUSSION}

\subsection{Agricultural Extension Information Dissemination Methods}

Approaches and methods used by agricultural extension services providers who own websites to disseminate information to smallholder farmers are shown in Figure 1.

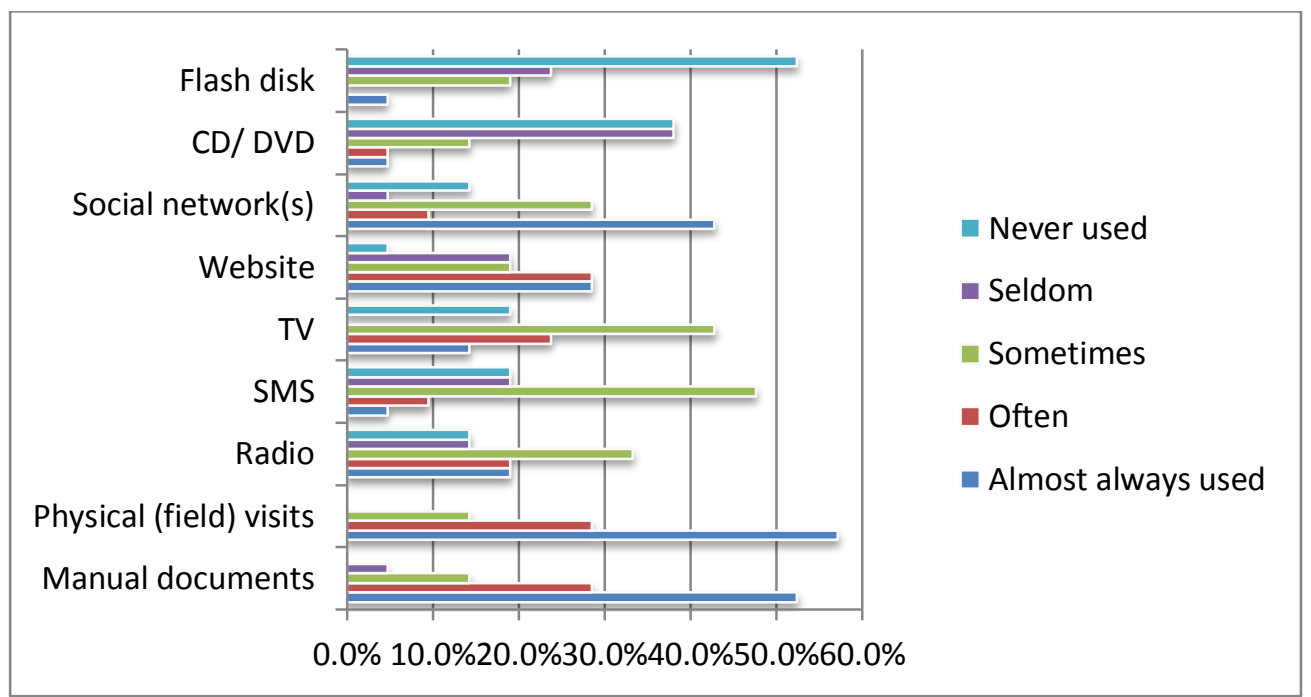

Figure 1: Agricultural extension information dissemination methods

The findings in Figure 1 shows (57\%) "almost always used" physical visits, (52\%) "almost always used" manual documents, $(43 \%)$ "almost always used" social networks, and (29\%) "almost always used" websites. Usage of websites (29\%) against that of social networks (43\%) is in line with [28] who note that there is low interest in using web information among rural farmers and the solution can be to repackage the information using social networks.

A review study [29] found that in Tanzania, channels used to deliver agricultural knowledge and information to smallholder farmers include mass media, friends and neighbours, extension officers, fellow farmers, non-government organizations, print materials and voice calls. A study [30] found farmers preferring training, demonstration, radios, workshops, mobile phones, and videos as channels for information dissemination. The findings of this study agree with both studies in that there are many methods and approaches agricultural extension services stakeholders use to deliver information to smallholder farmers.

Use of many methods and approaches by agricultural extension services providers to disseminate information to smallholder farmers means that smallholder farmers can choose the method(s) of receiving information. Depending on how the method is used by information disseminators and other factors, receivers of information might prefer one alternative(s) over the other(s). For the part of a website method of information dissemination can be how well the website is developed and used to disseminate information by information disseminators. But smallholder farmers will not be able to access information on the websites if they don't own devices used to access the websites, don't have knowledge and skills to access the information, or information disseminated do not have quality they desire.

\subsection{Pre-Website Development}

In pre-website development, this study focused on user involvement, purpose for developing websites, general contents of websites, and specific agricultural information contained in websites for farmers.

\section{Stakeholders' Involvement}

Figure 2 shows stakeholders involvement in initial stages of website development were "very high" for ICT/ IT people (76\%), management (52\%), and intended users (48\%). Involvements were "above average" for management (38\%), followed by specific department $(24 \%)$ as shown in figure 2. 


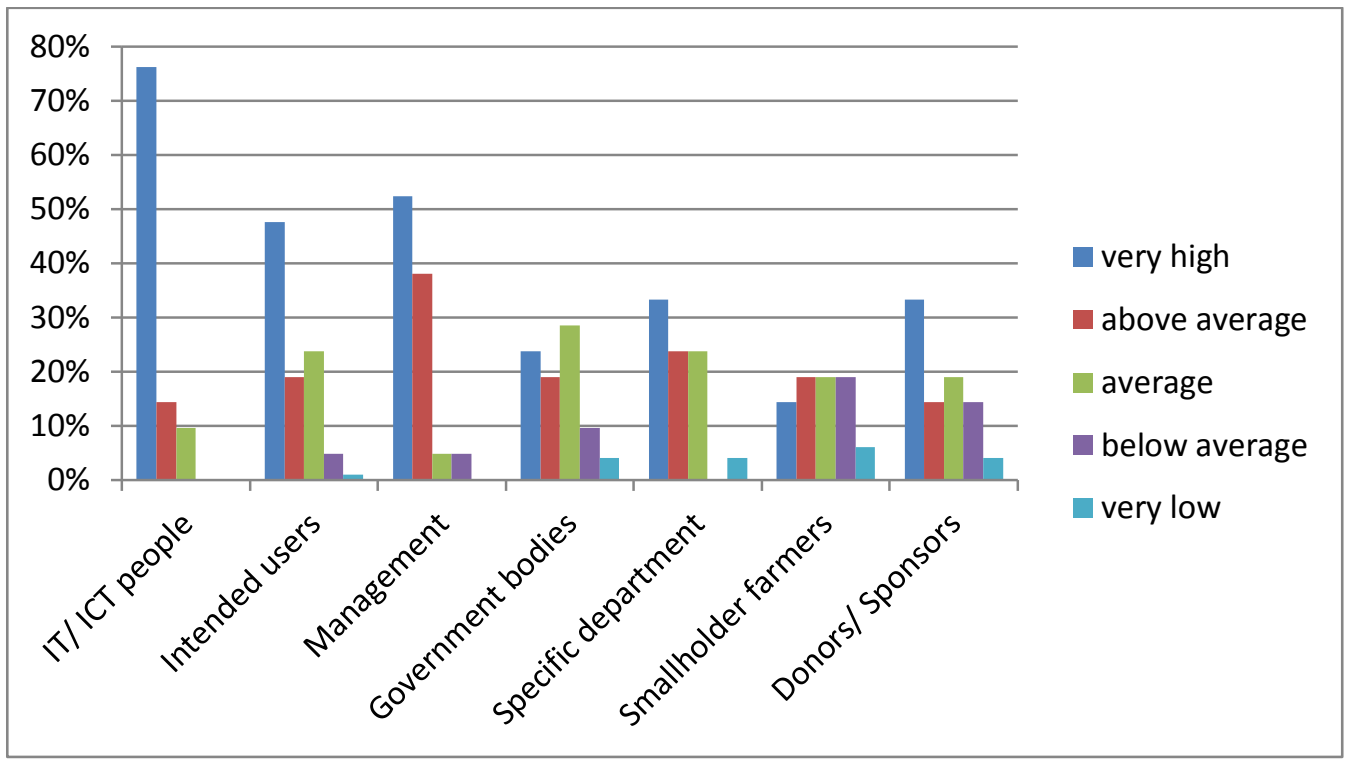

Figure 2: Stakeholders' involvement in initial stages of websites development

The [13] framework shows that in the first phase of website development the organization determines the objectives (purpose) of the website and the intended users of the website. This enables the developed website to contain the right content for the right users. Involvement of intended users of the websites for this study shown in Figure 2 was "very high" (48\%) and "above average" $(19 \%)$ and involvement of smallholder farmers was "very high" (14\%) and above average (19\%). Intended users of the websites constituted internal staff of the organization and people from outside organizations. These included customers, sellers, farmers, smallholder farmers and the general public.

An interview with one of the respondent on involvement of the 'to be' users of the websites revealed the following;

"I did prepare a layout of what I want to be in the website"

One respondent said the following on consulting smallholder farmers and their customers before commencement of website design and development project:

"We did not consult smallholder farmers. We know customers' needs through experience of interacting with them so we add content and information that suits them."

Another interview with a respondent who was ICT personnel from a government organization responded that;

"Users' involvement is expensive. We have many stakeholders that consulting all of them takes a lot of time and money but we know what information is important for them."

The [31] study points out that success of information systems depends on users' perceptions more than on their quality. A [32] study that reviewed 40 empirical studies on technology design concluded that user involvement matters for learning, adjusted design and increased sense of participation. Lack or minimal involvement of users is hence expected to negatively impact the success of the developed websites. This study found that the major focus of organizations was to develop websites that satisfy certain needs (requirements). However, requirements are important as documented in studies like [33][34] but they are not the only factor.

Lack and minimal involvement of users of the websites were noticed in this study even though some organizations seemed to be aware of the importance of involving users. Cost, approaches and methodologies for how to successfully carry out the involvement process might be a reason why there was overall minimal involvement of users. Not involving users in systems development normally results in including content and features that either the ICT personnel in the organization or the management or the developer or someone with influence perceive that is the right content and features to be included. Even though the content and features can be correct, but there might be another challenge of users perceiving that the system was not developed for them. Involving users from initial stages of information systems development ensures that the right content and features are included and increases the sense of users' ownership of the system. 


\section{Purpose for Developing Websites}

Figure 3 shows websites are "very important to staff (81\%), donors/ sponsors (71\%), government (57\%), specific departments (52\%), smallholder farmers $(47 \%)$ and the general public $(71 \%)$ ". No respondent rated her website to be "not important" to any of the category of stakeholders.

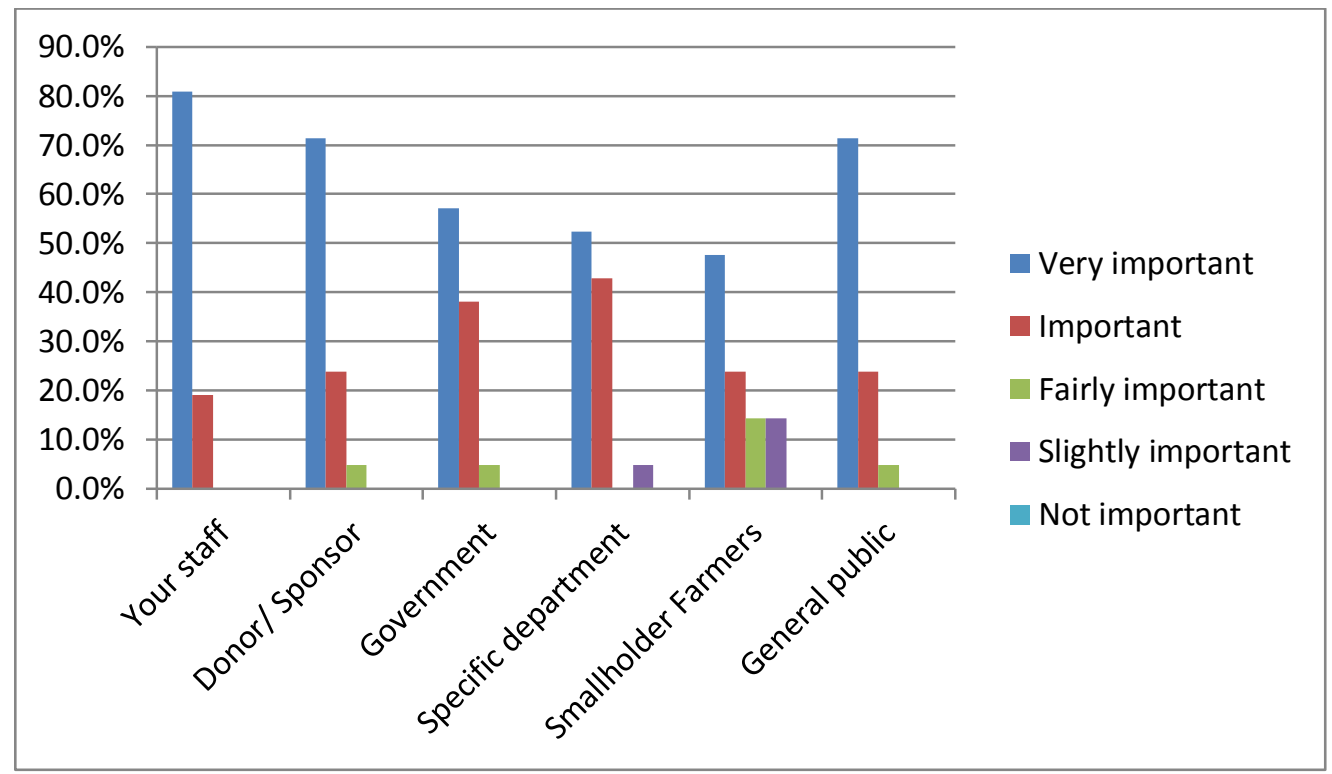

Figure 3: Purpose for developing websites

This shows that websites owned by agricultural extension services stakeholders in Tanzania were developed to address the information needs of diverse stakeholders as the purpose for developing the websites were for the websites to be "very important" to different stakeholders by majority of web owners (approximately $50 \%$ and above).

Websites reviews made for some of them found documents and information related to national policies, information on projects, vacancies, shares for the companies and advertisements for different products and services offered by an organization or their peers. These kinds of information were found to serve other users of the websites other than smallholder farmers. Both English and Swahili languages were found to be used in $80 \%$ of websites under study. This confirms the purpose intended by web owners to have websites that address information needs of various stakeholders - not just farmers. No website was found to be in local tribal language.

Availability of information on websites that do not have direct impact on farming to smallholder farmers and use of English language complicates access of information by smallholder farmers as explained by [6] and [12] that designing web information systems for smallholder farmers should be deep-rooted in a clear understanding of users' specific needs, dynamics and challenges.

\section{Contents of Websites of Agricultural Extension Services Providers}

Figure 4 shows that the websites contained information on contacts $(90.5 \%)$, about us $(85.7 \%)$, announcements $(85.7 \%)$, specific information for farmers (76.2\%), departments/ sections (66.7\%), and history/ background information (66.7\%). Figure 4 also shows the least contained information were mission and vision statements, news and galleries, training and projects and success stories each contained in only $(4.8 \%)$ of the websites under study. 


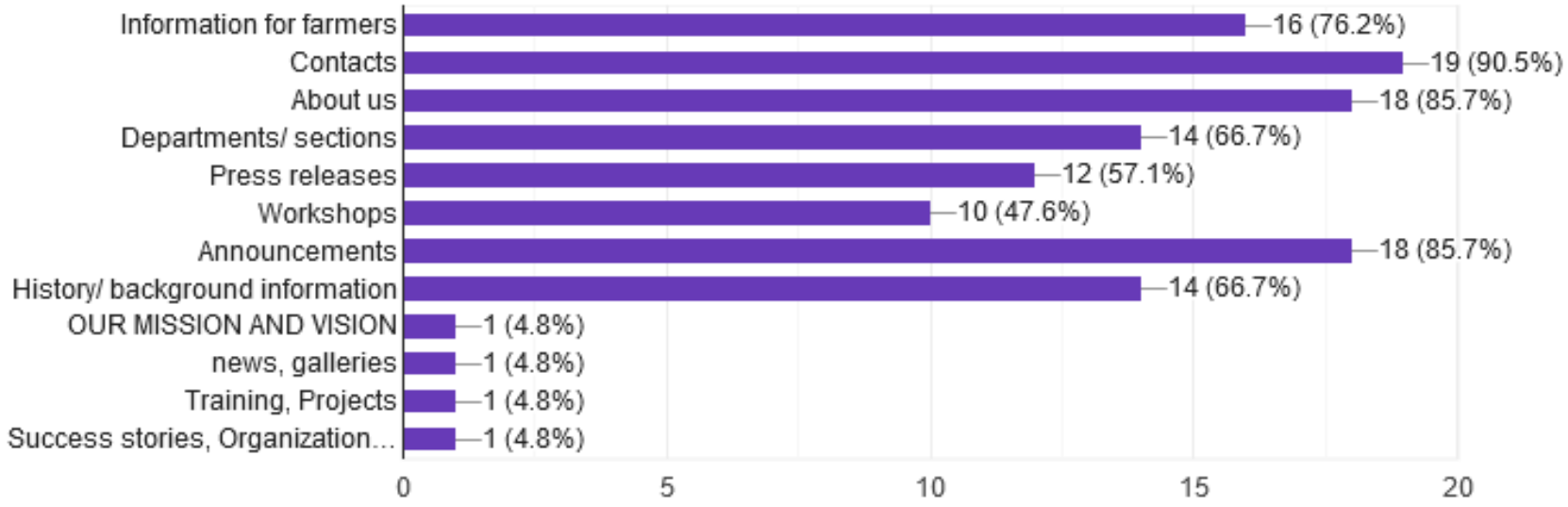

Figure 4: Contents of websites of agricultural extension services providers

Figure 4 shows approximately $25 \%$ of websites did not contain information intended for farmers. The study also found organizations use other means of disseminating agricultural extension information to smallholder farmers other than the Web. Therefore the $25 \%$ websites of organizations not using the websites to disseminate information to farmers use other methods to do the task.

\section{Agricultural Information Found in Websites for Smallholder Farmers}

Websites under study were found to contain specific information intended for farmers. These are shown in Figure 5: agriculture best practices $(71.4 \%)$, agriculture news (61.9\%), marketing news (47.6\%), and crop production and management information $(47.6 \%)$.

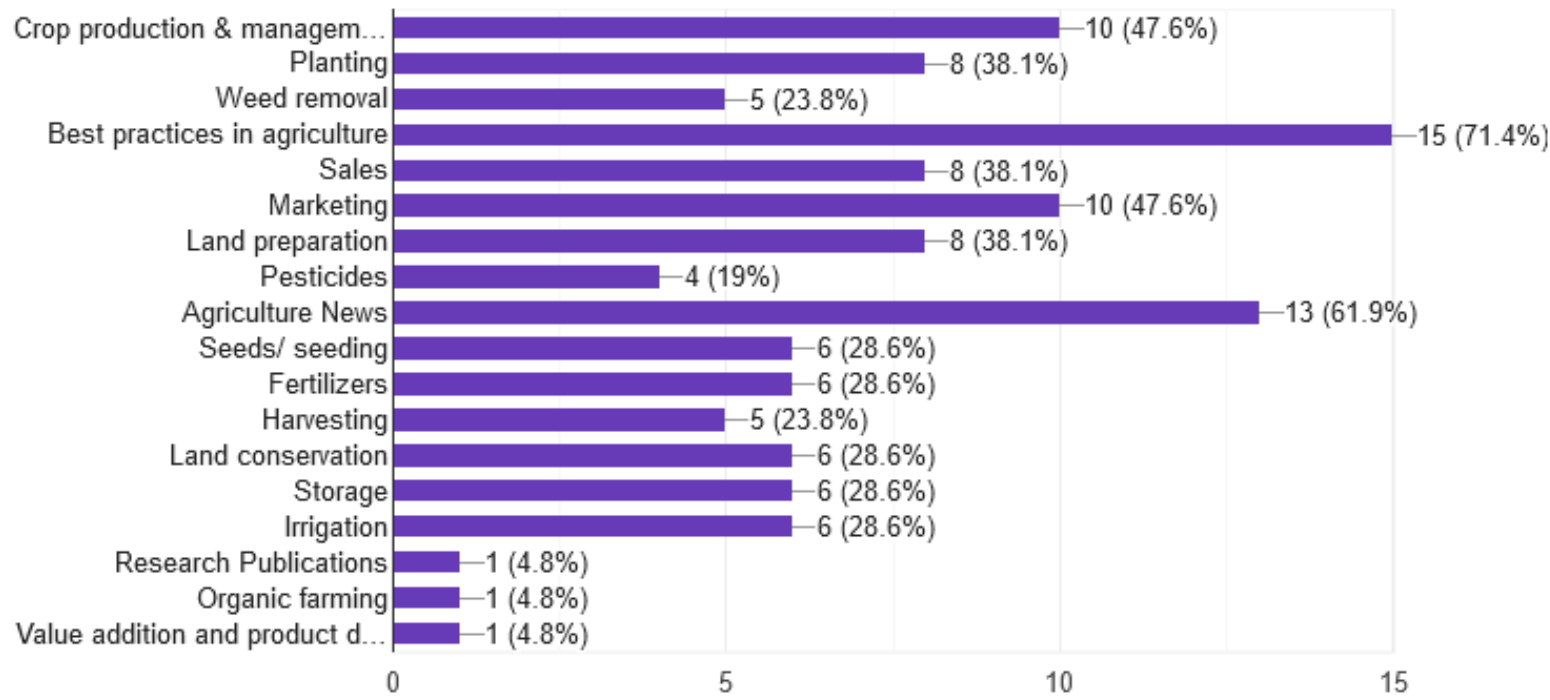

Figure 5: Agricultural information contained in websites for smallholder farmers

The variety of information found on the websites agree with findings by [35] and [36] who found that information on pest management, use of pesticides, soil improvement, weather forecast, market information, organic farming, use of fertilizers and best seed were mostly important hence required by smallholder and therefore agricultural extension services providers need to include them in their websites for smallholder farmers to access them. Also a study [30] found information needs of farmers spanning the entire crop value chain. However, for this study no website was found to contain information that spanned the entire crop value chain.

The variety of information found on websites is important because it shows smallholder farmers can easily get information related to farming if they visit the websites. Unlike information from Radios, TVs and physical visits, the presence of information on websites means that it is available 24 hours 7 days a week and can be accessed from any geographical location provided you have the devices, know-how, and internet connection. But this information on websites should possess quality attributes perceived to be important by smallholder farmers for him/ her to take trouble to access it. If the information is not useful or the usability of the website is not good it may hinder access of information. 


\subsection{During Website Development}

Issues examined in this stage are: 1) who developed the websites, and 2) communication.

\section{Developers of Websites for Agricultural Extension and Advisory Services}

The findings shows that the Electronic Government Authority (e-GA) of the United Republic of Tanzania developed 33.3\%, commercial companies $23.8 \%$, and $28.5 \%$ were built in-house by internal staff either on permanent employment or temporary employment as shown in figure 6.

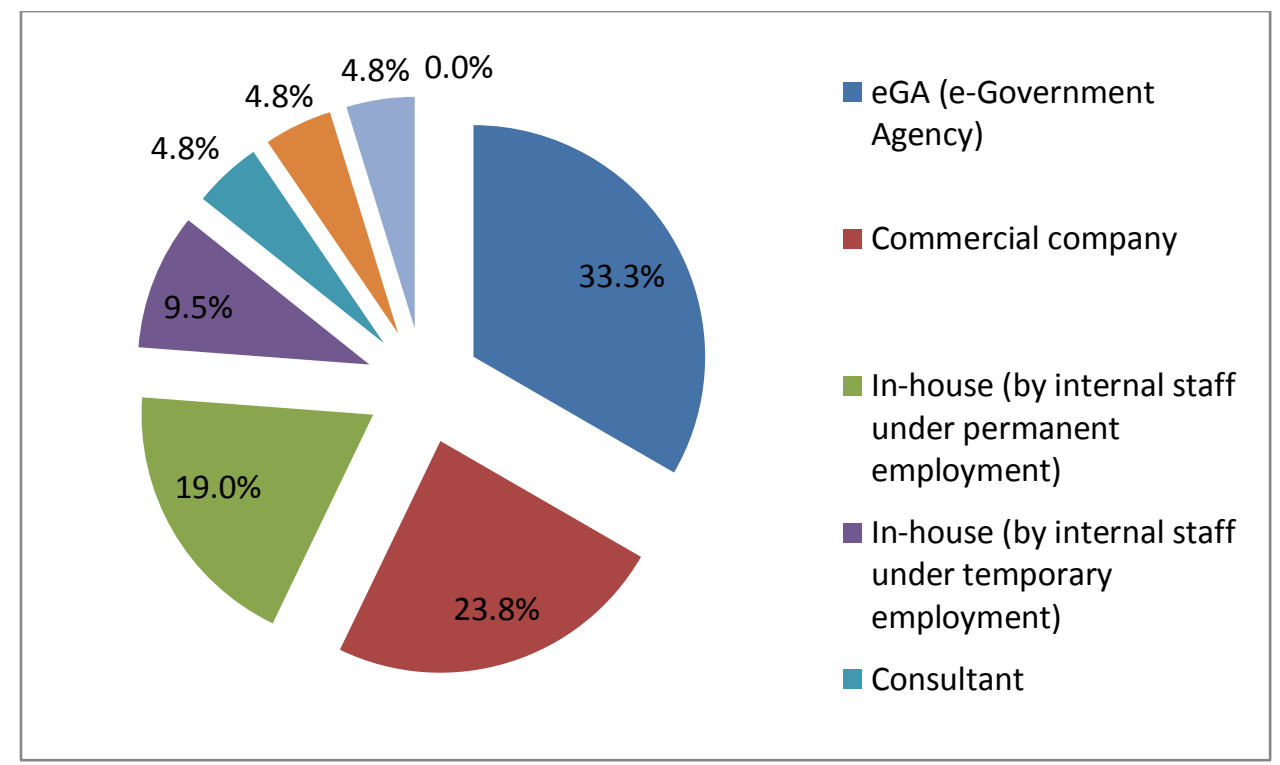

Figure 6: Developers of websites for agricultural extension and advisory services

All websites developed by e-GA were for public institutions and exhibited the same quality and feel though were developed for different organizations. Websites developed by other entities like commercial companies, staff, and volunteers were found to have huge variations in quality, look and feel. According to [37], e-Government Authority (e-GA) is "a public institution mandated to coordinate, oversee and promote e-Government initiatives as well as enforce e-Government related policies, laws, regulations, standards and guidelines in public institutions". It offers sustainable products and services to public institutions and the general public. E-GA can be consulted to develop a website for a public institution that does not have enough resources within to handle the job.

The study found that internal developments were carried out for organizations with internal staff capable of developing websites. This was common to private organizations with many employees. The second option was outsourcing development work. This was common to organizations with fewer employees (though for some larger organizations development was outsourced).

\section{4 . Communication}

Communication topics were grouped into three categories, namely; 1) on requirements, 2) on progress, and 3) on funding. Both internal development and external development needed communication on requirements for providing or clarifying them. Developers in both cases communicated progress of projects. Communication on funding was more noticed when development took place outside organizations. This is because when development work was done within organizations it was considered part of the employees' duties. A respondent from an organization with internal arrangement for website development said:

"We prepare the sketch and prototyping of the intended website, then the next step will be coding and programming, testing and validation will follow, thereafter is deployment to the live server."

Internal development was found to be easier for job completion because of easier communication and clarification of requirements from the organization as developers were aware of many things to be included on the websites and who to contact for what. A respondent from an organization carrying internal development was quoted saying:

"Since I have been employed at this institution, communication is very smooth (owner of website and developer belong to the same institution)."

Another one was quoted saying: 
"Easy communication because the developer was a volunteer in the organization."

A respondent from a private organization with website development external arrangement was quoted saying:

"When a developer develops our website, our involvement is much more on the appearance of the website."

And another one who had external arrangement said:

"During development we do progress monitoring with the developer to make sure all required content is placed as expected and it takes time".

A respondent from a public organization who had their website developed outside was quoted saying:

"Due to financial constraints we rarely communicate, though for now we are reconstructing our website through the ICT department in the Ministry of Agriculture."

And another one was quoted saying:

"The communication is easy to the developer but sometimes support from the developer is very difficult to get."

Communication is important during information systems development as pointed out by [34] and [38] who note that communication, motivation, processes and tools, relationships among stakeholders and requirements are essential in the success of information system development projects.

Building a quality website among others will require understanding of the intended users' needs, their strengths and limitations. For people involved with actual development of the websites intended for agricultural information dissemination they will need to communicate with appropriate people to learn this. Poor communication between the developer and the suppliers of requirements for the website will lead to websites that do not address content and features that were supposed to be addressed. To hire someone to develop your website is a partnership because communication, collaboration, and contribution between the developer and you as the website owner are necessary [39].

Even though for this study communication was found to be 'smooth' when development works were done within organizations, review of websites developed did not show that websites developed internally were of better quality compared to websites developed outside. A good quality website is one that addresses its users' needs and developed using better tools and technology which were not determined by whether development took place internally or not. Correct understanding of website users' needs, strengths, limitations and how the web can be used to disseminate this information and communicating to developers are essential in successful website design and development.

\subsection{Maintenance of Websites}

According to [13] framework, maintenance is a set of activities in the fourth (last) phase of website design and development responsible for continuing monitoring of the website to ensure it is operating and its contents and information are up to date. Under website maintenance the following were examined: 1) whether it is done internally or outside, and 2) frequency of maintenance.

\section{Where Maintenances were Carried}

The findings show that maintenance was done both inside and outside organizations. The decision whether to have internal or external maintenance was influenced by availability of personnel within organizations capable of carrying out the job. Organizations that did maintenance internally reported to have cheaper and easier maintenance as compared to organizations that have external maintenance arrangements. For example, a respondent from an organization that had arrangement for external maintenance was quoted saying:

"Website is maintained by external experts, and the contents are changed in months. Website maintenance is expensive hence we intend to use internal staff in the near future."

Personnel from an organization that carries internal maintenance was quoted saying:

"The website is maintained inside the organization. The content is changed usually on a weekly basis and sometimes daily depending on the availability of the content for sharing. We incur no cost for maintenance of our website."

Organizations, especially small ones might lack personnel with ICT skills to provide maintenance to their websites. Or personnel might be there but because the organization has a small number of staff they may decide to have external arrangements for other activities - website maintenance can be one of them. This is an added cost to the organization. On top of that, normally, the more frequent the external maintenance, the higher the cost to the organization.

Familiarity with organization's businesses and the fact that only one website is involved can give an edge to internal website maintenance over external one. With external maintenance there is a knowledge gap in website owner's businesses. Also many 
websites are maintained by the same organization/ personnel which could lead to lack of concentration to some of the tasks. Or communication challenges might exist between the website owner and the organization or personnel responsible for maintenance. Whether done inside or outside, a well worked out maintenance is required. This will entail frequently determining new content required and appropriately and conveniently adding it to the website. Also removing or changing the old content. For example, if the organization's website addresses coffee farming and a better pesticide or herbicide has been manufactured the website should be changed to capture new development.

\section{Frequency of Maintenances}

Frequency of maintenance varied from daily to monthly to very rare maintenance. Changing the structure of the websites and the content of the websites were the kind of maintenance performed. A respondent from a public institution was quoted saying:

During this phase the website is maintained by fixing bugs if any, content update and upgrading the website to new version of technology. The content of the website changed according to the requirement when needed.

Another one was quoted saying:

There must be a web structure maintenance schedule at least every 4 months, this will be done within the organization, the changing of contents will be done at any time, the cost of maintenance is covered by the institution itself.

This agrees with guidance from [39] that website changes should be made to both website content and design (structure). Changes in business and soliciting feedback from website visitors are among methods for assessing whether changes are required and how to best implement them [39].

Smallholder farmers' farming activities vary throughout the year and so is the need to have changes to information disseminated to them. The focus should be to disseminate information to smallholder farmers that is relevant at a particular time. Before content and information on websites are changed organizations should first be determining what information is currently required by farmers and how to best put it on their websites. Too frequent changes may not do well to farmers and information that has not been changed in years while on the ground there are so many changes will not help farmers either. Because websites were developed to address information needs of various users this may explain why for some organizations information changes were too frequent. For some, very rare maintenance was observed because websites were not regarded as convenient tools for information dissemination to farmers or because of issues of cost.

\section{CONCLUSION AND RECOMMENDATIONS}

Agricultural extension services providers use different methods to disseminate agricultural information to smallholder farmers, websites are one among them. Success of website development determines success of the developed website - its goal of meeting owner's objectives. This study shows that development is done in-house or outsourced and websites address information needs of varied stakeholders not just smallholder farmers. This makes websites contain so much information and as a result may constitute a challenge to information access by smallholder farmers. Web owners monitor the development and are responsible for providing all the requirements and there is little user involvement. Maintenance provides a way to ensure continued achievement of the intended objectives of the website.

The following are recommendations for stakeholders who own websites and provide agricultural extension services. Websites intended for providing agricultural extension services to smallholder farmers should be developed in such a way that they contain information relevant for that purpose only. The development should be users' (smallholder farmers') focused and their involvement should be central in the designs and development of websites. The development should be driven by the central need to disseminate information that possesses appropriate quality attributes from their point of view.

Web owners should hire capable website developers with enough resources, skills and experience to carry development work professionally. To reduce cost and improve quality of information disseminated contents for websites should be created and maintained internally by trained personnel for that purpose.

\section{REFERENCES}

[1] Food and Agriculture Organization of the United Nations. (2020). Agricultural Development Economics: Smallholder Family Farms. http://www.fao.org/economic/esa/esa-activities/smallholders/en/.

[2] Chapagain, T., \& Raizada, M. N. (2017). Agronomic challenges and opportunities for smallholder Terrace agriculture in developing countries. Frontiers in Plant Science, 8. https://doi.org/10.3389/fpls.2017.00331

[3] Paloma, S. G., Riesgo, L., \& Louhichi, K. (2020). The role of smallholder farms in food and nutrition security. Springer Nature. 
[4] Zerssa, G., Feyssa, D., Kim, D. G., \& Eichler-Löbermann, B. (2021). Challenges of Smallholder Farming in Ethiopia and Opportunities by Adopting Climate-Smart Agriculture. Agriculture (Switzerland), 11(3): 1-26.

[5] Danso-Abbeam, G., Ehiakpor, D. S., \& Aidoo, R. (2018). Agricultural extension and its effects on farm productivity and income: Insight from northern Ghana. Agriculture \& Food Security, 7(1). https://doi.org/10.1186/s40066-018-0225-x

[6] Barber, J., Mangnus, E., \& Bitzer, V. (2016). Harnessing ICT for Agricultural Extension (KIT Working Paper 2016:4). Royal Tropical Institute. https://213ou636sh0ptphd141fqei1-wpengine.netdna-ssl.com/sed/wpcontent/uploads/sites/2/2016/11/KIT_WP2016-4_Harnessing-ICT-for-agricultural-extension.pdf.

[7] Hawary, H. M. (2019). The Challenges of Agricultural Extension in Developing Agricultural Value Chains in Fayoum Governorate. IOSR Journal of Agriculture and Veterinary Science (IOSR-JAVS), 12(10): 8-24. https://www.iosrjournals.org/iosr-javs/papers/Vol12-issue10/Series-1/B1210010824.pdf

[8] Petros, M., Nachimuthu, D., Atinikut, M. H., \& Mohammed, M. (2018). Agricultural extension: Challenges of extension service for rural poor and youth in Amhara region, north western Ethiopia. The case of north Gondar zone. International Journal of Scientific Research and Management, 6(02). https://doi.org/10.18535/ijsrm/v6i2.ah02

[9] Andreev, O., Grebenkina, S., Lipatov, A., Aleksandrova, A., \& Stepanova, D. (2019). Modern Information Technology Development Trends in the Global Economy and the Economies of Developing Countries. Revista ESPACIOS, 40(42): 8-16. https://www.revistaespacios.com/a19v40n42/a19v40n42p08.pdf

[10] International Telecommunication Union. (2017). ICT trends in the LDCs. https://www.itu.int/en/ITU-D/LDCs/Pages/ICTFacts-and-Figures-2017.aspx

[11] Canada, Statistics. (2016). Compendium of Management Practices for Statistical Organizations from Statistics Canada's International Statistical Fellowship Program. https://www150.statcan.gc.ca/n1/en/pub/11-634-x/11-634-x2016001eng.pdf?st=9uKSPAOT.

[12] Misaki, E., Apiola, M., Gaiani, S., \& Tedre, M. (2018). Challenges facing sub-saharan small-scale farmers in accessing farming information through mobile phones: A systematic literature review. The Electronic Journal of Information Systems in Developing Countries, 84(4), e12034. https://doi.org/10.1002/isd2.12034

[13] Manhas, J. (2017). Initial Framework for Website Design and Development. International Journal of Information Technology. DOI 10.1007/s41870-017-0045-4

[14] Global Forumn for Rural Advisory Services. (2021). Major Institutions Providing Extension/advisory Services. https://www.g-fras.org/en/world-wide-extension-study/africa/eastern-africa/tanzania.html\#extension-providers

[15] IGI-Global. (2021). What is agricultural extension services. In IGI Global, International Academic Publisher. https://www.igi-global.com/dictionary/agricultural-extension-services/62379

[16] Food and Agriculture Organization of the United Nations. (1997). Guide to extension training. https://www.fao.org/3/t0060e/T0060E00.htm\#Contents

[17] Merriam-Webster. (2021). Definition of website. In Dictionary by: America's most-trusted online dictionary. https://www.merriam-webster.com/dictionary/website

[18] Collins English dictionary. (2021). Website definition and meaning | Collins Online Dictionary | Definitions, Thesaurus and Translations. https://www.collinsdictionary.com/dictionary/english/website

[19] Mozilla. (2021). What is a web server?. In MDN Web Docs. https://developer.mozilla.org/enUS/docs/Learn/Common_questions/What_is_a_web_server

[20] Zhang, Y., Wang, L., \& Duan, Y. (2016). Agricultural information dissemination using ICTs: A review and analysis of information dissemination models in China. Information Processing in Agriculture, 3(1), 17-29.

https://doi.org/10.1016/j.inpa.2015.11.002

[21] Etwire, P. M., Buah, S., Ouédraogo, M., Zougmoré, R., Partey, S. T., Martey, E., Dayamba, S. D., \& Bayala, J. (2017). An assessment of mobile phone-based dissemination of weather and market information in the Upper West Region of Ghana. Agriculture \& Food Security, 6(1). https://doi.org/10.1186/s40066-016-0088-y

[22] Barakabitze, A. A., Fue, K. G., \& Sanga, C. A. (2017). The use of participatory approaches in developing ICT-based systems for disseminating agricultural knowledge and information for farmers in developing countries: the case of Tanzania. The Electronic Journal of Information Systems in Developing Countries, 78(1), 1-23. https://doi.org/10.1002/j.16814835.2017.tb00576.x

[23] Walters, S. A., Broady, J. E., \& Hartley, R. J. (1994). A review of information systems development methodologies. Library Management, 15(6). https://doi.org/10.1108/01435129410067331

[24] Saeed, S., Jhanjhi, N. Z., Naqvi, M., \& Humayun, M. (2019). Analysis of software development methodologies. International Journal of Computing and Digital Systems, 8(5), 445-460. https://doi.org/10.12785/ijcds/080502

[25] Akinsola, J. E., Ogunbanwo, A. S., Okesola, O. J., Odun-Ayo, I. J., Ayegbusi, F. D., \& Adebiyi, A. A. (2020). Comparative analysis of software development life cycle models (SDLC). Intelligent Algorithms in Software Engineering, $310-322$. https://doi.org/10.1007/978-3-030-51965-0_27 
[26] World Bank climate change knowledge Portal. (2021). World Bank Climate Change Knowledge Portal. https://climateknowledgeportal.worldbank.org/country/tanzania-united-republic

[27] European Commission. (2016). Micro-, Small- and Medium-Sized Enterprises: Definition and Scope. European Comission. https://eur-lex.europa.eu/legal-content/EN/TXT/?uri=legissum:n26026\%0Ahttp://eur-lex.europa.eu/legalcontent/EN/TXT/?uri=LEGISSUM:n26026.

[28] Mbagwu, F. C., Oyemike, V. B., \& Onuoha, C. O. (2018). Challenges of Meeting Information Needs of Rural Farmers through Internet-Based Services : Experiences from Developing Countries in Africa. http://library.ifla.org/2195/1/166mbagwu-en.pdf.

[29] Ndimbwa, T., Mwantimwa, K., \& Ndumbaro, F. (2019). Channels used to deliver agricultural information and knowledge to smallholder farmers. IFLA Journal, 47(2), 153-167. https://doi.org/10.1177/0340035220951828

[30] Opolot, H.N., Obaa, B.B., Isubikalu, P., Ebanyat, P. \& Okello, D. (2016). Quality and dissemination of information for strengthening University-farming community engagement in northern Uganda, African Journal of Rural Development (AFJRD), AFrican Journal of Rural Development (AFJRD), 1(1).

[31] Chevers, D. A., \& Grant, G. G. (2017). Information Systems Quality and Success in Canadian Software Development Firms. Information Resources Management Journal, 30(3), 1-25. https://doi.org/10.4018/irmj.2017070101

[32] Fischer, B., Peine, A., \& Östlund, B. (2019). The importance of user involvement: A systematic review of involving older users in technology design. The Gerontologist, 60(7), e513-e523. https://doi.org/10.1093/geront/gnz163

[33] Lane, S., O’Raghallaigh, P., \& Sammon, D. (2016). Requirements gathering: The journey. Journal of Decision Systems, 25(sup1), 302-312. https://doi.org/10.1080/12460125.2016.1187390

[34] Iqbal, J., Ahmad, R. B., Khan, M., Fazal-e-Amin, Alyahya, S., Nizam Nasir, M. H., Akhunzada, A., \& Shoaib, M. (2020). Requirements engineering issues causing software development outsourcing failure. PLOS ONE, 15(4), e0229785. https://doi.org/10.1371/journal.pone.0229785

[35] Sikoro, A. (2016). ICT based agricultural information distribution framework for small scale farmers: a case of Kondoa district council [Master's thesis]. http://repository.udom.ac.tz/bitstream/handle/20.500.12661/969/ALLY\%20SIKORO\%20$\% 20 \mathrm{MSC} \% 20 \mathrm{CS}$.pdf?sequence=1\&isAllowed=y

[36] Mubofu, C. \& Elia, E. (2018). Disseminating Agricultural Research Information: A Case Study of Farmers in Mlolo, Lupalama and Wenda Villages in Iringa District, Tanzania. University of Dar es Salaam Library Journal, 12(2): 80-97.

[37] Electronic Government Authority | Sisi Ni Nani. (2021). e-GA | Mwanzo. https://www.ega.go.tz/who-are-we

[38] Salman, A., Jaafar, M., Malik, S., Mohammad, D., \& Muhammad, S. A. (2020). An Empirical Investigation of the Impact of the Communication and Employee Motivation on the Project Success Using Agile Framework and Its Effect on the Software Development Business. Business Perspectives and Research, 9(1), 46-61. https://doi.org/10.1177/2278533720902915

[39] Pennsylvania state university extension (2021). Developing and maintaining a website. Https://extension.psu.edu/developingand-maintaining-a-website 